DOI: 10.11606/issn.2318-8855.v7i7p83-96

\title{
Mulher negra, trabalho e resistência: escravizadas, libertas e profissões no século XIX
}

Karoline Nascimento Miranda*

Resumo: Esta produção se destina, a partir de uma análise de diversas perspectivas, contribuir para a pesquisa historiográfica acerca das mulheres negras dentro do século XIX, tanto libertas quanto escravas, inseridas no contexto de uma sociedade escravista e suas hierarquizações sociais. O objetivo é contar a história do século XIX do ponto de vista da figura mais baixa da pirâmide social: a mulher negra, resultado da opressão de gênero e de raça, a qual a historiografia é tão parca. Podemos, a partir disso, estudar como eram suas relações sociais e como o trabalho - nosso objeto de estudo no curso - se dava nessas condições.

Palavras-chave: escravas, livres, trabalho, mulher, negra

\section{Uma reflexão acerca da História social do trabalho negro}

O mundo do trabalho é um objeto de estudo largamente explorado por historiadores em todo o mundo. A contribuição da escola marxista inglesa, a partir das obras de Thompson e Hobsbawm, nos ajudaram a construir muitos dos conceitos que hoje, parecem inatos ao historiador: consciência de classe, organização sindical, exploração do trabalhador. Mas as origens do trabalho no Brasil, bem como em toda a América Latina, tem peculiaridades que a historiografia procura dissociar deste conceito: a escravidão. Álvaro Nascimento aponta isso

\footnotetext{
* Graduanda em História pela Universidade do Estado do Rio de Janeiro (Uerj) e graduanda em Jornalismo pelo Centro Universitário Carioca (Unicarioca). Membra do grupo de estudos "Brasil do século XIX: História social do trabalho, da escravidão e das cidades" e monitora de História do Brasil Republicano na Uerj. E-mail: karoline.miranda04@gmail.com
} 


\section{artigos}

\section{Karoline Nascimento Miranda}

como um grande erro a ser reparado por seus colegas historiadores, como sendo algo perpetuador do racismo e do rompimento do historiador com os fatos históricos.

O grande fato é que a historiografia acerca dos negros e negras perpassou por inúmeros elementos que a deslegitimaram: em um primeiro momento, a coisificação do escravizado o tornava uma mera mercadoria - que em muitos casos, trazia problemas, carecendo das autoridades policiais -, o que facilitou em muito a utilização das fontes que contabilizavam os escravizados e dos registros policiais da época, mas que o tornava desinteressante demais para uma produção melhor acerca dele; no pós-abolição, a tentativa de embranquecimento da população tornava o negro algo indesejável, como uma doença a ser erradicada da sociedade, logo, algo evitado de ser colocado em questão para a historiografia. Podemos concluir então, que o racismo, embora combatido, foi perpetuado pela falta de debate e de certa forma, veladamente apoiado. (NASCIMENTO, 2016, p.610)

Os recortes temporais "cirúrgicos" evidenciados nas pesquisas (NASCIMENTO, 2016, p.617) são claramente, como apontou Silvia Lara, uma tentativa de separar "dois Brasis": o pré e o pós 1888. Nessa divisão, os estudos sobre o trabalho começam a partir do trabalho assalariado e livre, excluindo como um todo o trabalho escravo e suas especificidades. Segundo a autora, isentar a história social do trabalho da pesquisa e do estudo das perspectivas da escravidão enquanto elemento pertencente ao seu ramo é ocultar esses trabalhadores e a riqueza gerada por eles durantes séculos, "em um piscar de olhos". (LARA, 1998, p.26) Silvia ainda nos esclarece que essa transição do trabalho escravo para o livre, temporalmente fixado no final do século XIX e caracterizado como substituição do escravo pelo assalariado nas obras sobre o assunto revela uma ruptura radical, que não denota a intensidade de relações e acomodações entre esses agentes históricos e provoca um apagamento real dos negros, antes escravizados, dentro dos mundos do trabalho livre, relegando-os a um passado evitado e que pretende ser esquecido.

Dentro desse campo racial, há ainda um outro recorte que reduz ainda mais as produções acerca do tema: o de gênero. Desde sempre, o patriarcado oprimiu e reprimiu 


\section{artigos}

Mulher negra, trabalho e resistência: escravizadas, libertas e profissões no século XIX mulheres, e o que sabemos historicamente sobre elas ainda é muito pouco, visto que elas praticamente viviam para não existir socialmente, culturalmente, politicamente nem economicamente. Recentemente, contudo, os estudos sobre mulheres na história vêm se ampliando, e a historiografia reservou um melhor olhar para elas.

O debate sobre gênero sugere, desde já, alguns apontamentos. Em A Mulher na História do Brasil, Mary del Priore enfatiza, pertinentemente, que é necessário afastar da história das mulheres um olhar vitimizante e passivo, no qual a mulher apenas é o sujeito oprimido e receptáculo das ações patriarcais da sociedade. Margareth Rago explicita que, ao nos debruçarmos sobre os primeiros ensaios de uma história social da mulher, esbarraremos nesta mesma barreira, com fortes raízes marxistas. "As péssimas condições de trabalho, os salários inferiores aos dos homens, o assédio sexual, as inúmeras formas da violência machista foram temas que ocuparam as páginas das obras que se dedicaram à mulher trabalhadora e que acabaram por identificá-la como produto das determinações econômicas e sociais, vítima das injunções do sistema, dando pouco destaque à sua dimensão de sujeito histórico, consciente e atuante" (RAGO, 1995, p.82). Embora seja um objeto social que sofre a opressão patriarcalista, a mulher também é agente de resistência, seja por meio da luta ou da subversão. Isso se dá mais intrinsecamente ao falarmos sobre nosso real objeto: mulheres negras.

Apesar de tratar do recorte de gênero e raça nos EUA, as ideias de Angela Davis transpassam os limites geográficos quando destacam que "proporcionalmente, as mulheres negras sempre trabalharam mais fora do que suas irmãs brancas." (DAVIS, 2016, p.17). Sendo assertiva na ausência, muitas vezes, da intersecção racial na perspectiva do estudo de gênero, Davis enfatiza que, enquanto para as mulheres brancas, o trabalho era algo a se discutir e conquistar, para as negra, ele sempre existiu, inclusive como um objeto de exploração, e isso repercutia geralmente pelos papeis sociais que ambas desempenhavam na sociedade capitalista, que recriou seus personagens - sociedade essa que só tratava como personagem "mulher" aquela que, naturalmente, tinha direito a isso: a branca. "Na propaganda vigente, 


\section{artigos}

\section{Karoline Nascimento Miranda}

'mulher' se tornou sinônimo de 'mãe' e 'dona de casa', termos que carregavam a marca fatal da inferioridade. Mas, entre as mulheres negras escravas, esse vocabulário não se fazia presente. Os arranjos econômicos da escravidão contradiziam os papéis sexuais hierárquicos incorporados na nova ideologia. Em consequência disso, as relações homem-mulher no interior da comunidade escrava não podiam corresponder aos padrões da ideologia dominante." (DAVIS, 2016, p.25).

A questão da fragilidade feminina, também refutada por Davis (DAVIS, 2016, p.20), também é debatida por Sueli Carneiro. Às mulheres negras, fossem elas libertas, livres ou escravizadas, não era dado o direito de serem "frágeis", principalmente por estarem profundamente enraizadas ao mundo do trabalho. "Quando falamos do mito da fragilidade feminina, que justificou historicamente a proteção paternalista dos homens sobre as mulheres, de que mulheres estamos falando? Nós, mulheres negras, fazemos parte de um contingente de mulheres, provavelmente majoritário, que nunca reconheceram em si mesmas esse mito, porque nunca fomos tratadas como frágeis. Fazemos parte de um contingente de mulheres que trabalharam durante séculos como escravas nas lavouras ou nas ruas, como vendedoras, quituteiras, prostitutas (...) Fazemos parte de um contingente de mulheres com identidade de objeto. Ontem, a serviço de frágeis sinhazinhas e de senhores de engenho tarados." (CARNEIRO, 2011).

Estar inserida no mundo do trabalho era, então, abdicar de todo o papel feminino proveniente da sociedade capitalista. Entretanto, ser negra era simplesmente não ser julgada por isso, a partir do momento em que era somente esse o esperado dela, essa era a sua função social: reproduzir e trabalhar. Entremeado nesse aparentemente simples binômio funcional porém, há questões profundas que precisam ser tratadas: a impossibilidade do cuidado com os próprios filhos, a negação ao direito do lar e da família, a falta de expectativa de matrimônio, expectativas que, para uma mulher do século XIX, eram perfeitamente plausíveis e ainda assim, impraticáveis. Isso reflete diretamente no mundo de trabalho e suas respectivas funções dentro dele. 


\section{artigos}

Mulher negra, trabalho e resistência: escravizadas, libertas e profissões no século XIX

Entretanto, tratar de mulheres negras - principalmente as escravizadas - ainda é procurar uma agulha no palheiro da historiografia. Difícil é achar fontes sobre elas por elas mesmas - diários, registros, entrevistas. Fora das luzes da imprensa, da educação e alfabetização e das luzes da ribalta historiográfica, começamos de um ponto de partida com “evidente desvantagem" (NEPOMUCENO, 2013, p.385).

\section{O trabalho rural e o trabalho urbano e seus impactos na mulher negra}

O recorte de gênero é fundamental para entender o trabalho específico da mulher negra escravizada e sua resistência a partir dele - e após ele. A começar, a escrava mulher valia muito menos do que o escravo homem, e essa proporção continuava após a compra pelo senhor. Os grandes fazendeiros demandavam escravos homens jovens e fortes, com idade entre 15 e 25 anos, pela sua maior capacidade em exercer trabalho pesado na lavoura. As escravas, em seu valor de compra, eram 20\% mais baratas do que os escravos. (DIAS, 2013, p.362) Cecília Moreira Sales, em seu artigo sobre as ganhadeiras de Salvador, coloca que uma escrava de ganho conseguia pagar ao seu senhor a taxa pelo seu serviço, como lavadeira ou engomadeira, por volta de 240 réis ao dia; já um escravo carregador de cadeiras conseguia pagar em torno de 400 réis. (SALES, 1996, p.58)

O trabalho da mulher negra nas fazendas, embora desprezado, chegava a corresponder metade dos grupos trabalhadores. Apesar de consideradas quase sempre incapazes e mais fracas, as escravizadas faziam o trabalho árduo no campo e na lavoura, muitas vezes com os seus filhos à tira colo. A gravidez não era respeitada, tampouco colocada como condição de cuidado. As escravizadas grávidas trabalhavam de sol a sol, não se livrando de nenhuma forma de castigos e executando os mesmos serviços ou até mais pesados do que antes de engravidar. Maria Odila explicita o assunto, ao contar um caso de uma negra, que, mesmo em estágio avançado da gravidez, foi mandada para o cafezal; sentido muitas dores, ela se retirou para a senzala com o que tinha colhido. No caminho, ocorreu o parto e com o desgaste, ela desmaiou; ao acordar, "os porcos haviam dilacerado a criança". (DIAS, 2013, p.363). As escravizadas também eram aproveitadas na casa-grande, servindo às sinhás 


\section{artigos}

\section{Karoline Nascimento Miranda}

como cozinheiras, arrumadeiras, mucamas, amas-de-leite para o filho de suas senhoras e futuramente, amas-secas.

De início, os filhos das escravizadas constituíam maior peso e oneravam mais do que comprar uma criança escrava para o trabalho. Logo, os senhores não hesitavam a separar famílias, e as mulheres viam seus filhos serem vendidos e talvez, nunca mais vistos. Entretanto, a visão mudou depois de um tempo; não raro, as escravizadas eram estimuladas ao concubinato com vários homens, a fim de procriarem mais escravos para o seu senhor. Para além disso, o próprio senhor se dispunha sexualmente de suas escravas, o quanto queria e quando queria, e se não o servissem, eram expostas a castigos e humilhações de todas as sortes. O estupro foi responsável por grande parte dos filhos bastardos, mulatos e cafuzos que vinham a servir a fazenda, posteriormente.

Nas grandes propriedades rurais, as escravizadas procuravam, no trabalho, criar uma forma de resistência e até de liberdade, como diz Maria Odila Dias neste trecho:

Boas cozinheiras, engomadeiras e lavadeiras eram requisitadas para prestar serviços na sede da fazenda. As escravas domésticas, as mucamas, eram poupadas dos trabalhos mais pesados da lavoura e podiam andar mais bemvestidas e limpas. Na casa-grande, usavam roupas no estilo europeu, mas as que iam e vinham, como as lavadeiras e as passadeiras, ousavam manter seus turbantes e saias de bicos, conservando os penteados e os estilos de vestir de suas terras de origem e do seu grupo étnico. Pra as suas festas e batuques, as escravas que serviam à casa-grande conseguiam ostentar acessórios. Amuletos, figas, estrelas de Davi, vestimentas coloridas inacessíveis para a maioria das escravas que trabalhavam na terra (DIAS, 2013, p.375).

Um cenário de fortíssima presença feminina negra era, como não poderia deixar de ser, o ambiente doméstico, tanto nas grandes propriedades rurais, como - e principalmente no meio urbano. O trabalho de Sandra Lauderdale Graham, intitulado Proteção e Obediência criadas e seus patrões no Rio de Janeiro 1860-1910 é o mais extenso e completo trabalho sobre o assunto já publicado, o que o faz único para a historiografia, de certa forma. Voltando o olhar para o ambiente privado, a autora coloca as relações serviçais - tanto livres quanto escravas - em um paradoxo de proteção e obediência: as criadas, subservientes, deviam aos 


\section{artigos}

Mulher negra, trabalho e resistência: escravizadas, libertas e profissões no século XIX seus senhores obediência, trabalho bem feito e atender às suas exigências (inclusive sexuais); em troca, recebiam deles proteção contra o mundo externo, que era considerado "perigoso" a toda e qualquer mulher - inclusive às negras. (GRAHAM, 1992, p.15).

Essa visão, de certa forma, nos dá uma ambiguidade de visão da presença feminina negra no espaço público: de um lado, ela nos traz a ausência de uma perspectiva de que a mulher negra já estava inserida no espaço da rua, sendo inclusive de certa forma pertencente a esse espaço geográfico, em contraste à mulher branca; por outro lado, Graham nos mostra ainda assim a fragilidade destes corpos negros femininos no espaço público, que, visivelmente necessitadas de "proteção", ainda eram vistos como corpos passíveis de serem tocados, usados e lesados, ou seja, objetificados, a partir do momento em que estando a mulher negra "desprotegida" nesse espaço público, também seu corpo é um corpo público.

No que concerne às ocupações destas criadas, “(...) inclui, em um extremo, as mucamas e amas-de-leite e, no outro, as carregadoras de água ocasionais, as lavadeiras e costureiras. Até mesmo as mulheres que vendiam frutas, verduras ou doces na rua eram geralmente escravas que, com frequência, desdobravam-se também em criadas da casa durante parte do dia." (GRAHAM, 1992, p.18)

Justamente do meio doméstico é que saiu a maioria das escravizadas que migravam para a cidade; as mais bonitas, com mais jeito, mais "ladinas" (SALES, 1996, p.61), espertas, inquietas e habilidosas conseguiam seu lugar como escravas de ganho na cidade. Era, de fato, um comércio clandestino que não respeitava os preços tabelados pelas autoridades municipais - até certa altura; os ganhadores (escravizados homens) tinham que cumprir exigências formais burocráticas, mas não as ganhadeiras (REIS, 1993, p.8); embora as autoridades sempre tentassem um controle seguro (SALES, 1996, p.65-66).

No meio urbano, as famosas ganhadeiras, escravas de ganho que lucravam vendendo toda a sorte de secos e molhados (REIS, 1993, p.8), como hortaliças, verduras, peixes, frutas, comida pronta, fazendas ou louças (SALES, 1996, p.59), além de alugarem seus serviços 


\section{artigos}

\section{Karoline Nascimento Miranda}

domésticos de passadeira, arrumadeira ou lavadeira (DIAS, 201, p.376). O ganho tinha características muito peculiares em relação aos outros tipos de escravização; dava muito maior liberdade de trânsito ao trabalhador escravizado, e oferecia uma oportunidade única: acumular seu próprio dinheiro para próprio sustento, ou até mesmo, a compra de sua alforria - desde que a maior parte fosse dedicada ao seu senhor.

As ganhadeiras tinham uma configuração de trabalho muito diferente; vendiam ou alugavam seus próprios serviços, o que as tornava donas, de certa forma, de seu próprio negócio. Representaram, nas grandes cidades, principalmente Rio de Janeiro, Salvador, São Paulo e Belo Horizonte, uma parte fundamental do comércio e circulação do mercado.

Segundo um censo de africanas no ganho na cidade de Salvador, pesquisado por Cecilia Moreira Sales, as ganhadeiras no comércio eram a maioria e ganhavam mais do que as escravizadas de ganho que se dedicavam aos serviços domésticos. As "mercadejas", "quitandeiras", de "negócios" e de "ganho" eram a maioria no censo. A tarefa de vendeira exigia faro para o negócio, a e a todo o tempo se buscavam negras de "grande tino comercial". Era importante que as escravizadas desempenhassem a função com habilidade em atrair e conquistar a clientela, com a qualidade de seus produtos e preços que agradassem.

O ganho também possibilitava às escravizadas angariarem o sustento de sua própria família e aos poucos, se desvencilharem de seus senhores, mesmo legalmente ainda sob seu domínio; muitas escravas, dependendo da boa vontade de seus donos, não moravam com eles, possuindo assim autonomia residencial. (SALES, 1996, p.59). O pequeno negócio de uma ganhadeira garantia o sustento de seus próprios filhos, sem depender de ninguém, pois muitas vezes, eram sozinhas e chefes de família.

Em Salvador, com o tempo, as ganhadeiras praticamente monopolizaram a distribuição de peixes, carnes, verduras e até contrabandeados, se tornando notavelmente um risco para as autoridades municipais, pela intensa movimentação ao seu entorno, 


\section{artigos}

Mulher negra, trabalho e resistência: escravizadas, libertas e profissões no século XIX independência e liberdade que conquistaram. Viraram uma figura imprescindível, ao ponto de um viajante relatar que "sem as negras vendeiras das ruas, seria praticamente impossível viver no Rio de Janeiro, Salvador e Recife durante os século XVIII e XIX." (SALES, 1996, p.67). A figura da ganhadeira é tão forte que, até hoje, ainda existe em nosso imaginário o famoso "comércio de tabuleiro", originário das escravizadas de ganho do setecentos e oitocentos.

Nos é muito caro observar, também, a resistência cultural que as mulheres negras exerciam a partir de seu trabalho - seja ele rural ou urbano. O trabalho de Marcelo Paixão e Flávio Gomes enriquece o estudo das mulheres negras a partir desta ótica, ao destacar que a linguagem e as cantigas, principalmente nas plantações durante o trabalho, era um meio de educação de seus filhos, a manutenção da família e disseminação de sua própria cultura e resistência (GOMES \& PAIXÃO, 2008, p.951).

Independentemente do espaço rural ou urbano, a mulher negra sofreu com a presença do trabalho escravo, subjugando-a além do gênero e da raça, ao estigma da escravidão, que impactou e racializou as relações de trabalho patrão-empregada quando em situações de forra e, inclusive, perdurando após a abolição. O tratamento senhorial nas relações de trabalho onde está inserida a mulher negra são resultado de uma estrutura, um fenômeno de longa duração que coloca a trabalhadora em papel diretamente servil à seu patrão, principalmente no que tange aos serviços domésticos.

\section{A mulher negra e o trabalho livre}

Ser liberta não eximia as mulheres do ônus de viver em uma sociedade escravista. As forras enfrentavam inúmeros preconceitos, eram acusadas de 'levar vida airada', de não ter moral. Eram constantemente abordadas pelas autoridades como se fossem escravas fugidas e algumas chegavam a ser presas várias vezes, amargando processos judiciais para comprovar o seu status de liberta. Muitas chegavam a ser raptadas, reescravizadas e revendidas como escravas. (DIAS, 2013, p. 377-378).

A liberdade constituía um sonho doce, porém, de consequências amargas. A dificuldade em se afirmar como mulher livre, muitas vezes, ocorria no interior da própria 


\section{artigos}

\section{Karoline Nascimento Miranda}

família (DIAS, 2013, p.378), com relação aos homens e sua raiva pela liberdade adquirida pelas esposas indo parar na polícia e nas autoridades. O patriarcado mais uma vez, nesse ínterim, cumpre seu papel: embora ligados pela raça, o homem se sobrepõe a mulher no papel social patriarcal, como 'chefe da família'. Tanto que os motivos não paravam por aí: os processos criminais registram que uma vez estando livre, a mulher se negava a fazer sexo com o marido; o marido, vendo-a liberta, proibia-a de circular pela cidade ou negava-lhe o direito ao trabalho. Isso resultava em inúmeras agressões. A cultura machista e patriarcalista fazia com que a mulher casada, muitas vezes, só trocasse de senhor.

De uma forma geral, as libertas trabalhavam, e muito. As ganhadeiras libertas conseguiam lucrar muito mais, pois não precisavam pagar taxas a nenhum senhor. (SALES, 1996, p.58-59). Mulheres trabalhavam como quitandeiras, lavadeiras, costureiras ou taverneiras, e tinham orgulho de sua autonomia financeira. Geralmente eram mulheres independentes, pois tinham conseguido sua própria liberdade com o suor de seu próprio trabalho.

Com o tempo, próximo ao fim do século XIX, as alforrias se ampliaram até as áreas rurais. As roceiras passaram à vendedoras, quitandeiras e chegando à cidade mais facilmente, conseguiam comprar sua própria liberdade. Entretanto, a "suposta honra masculina" permaneceu as mantendo em uma violência e em muitas vezes, cárcere, dentro da própria família, nas mãos dos próprios maridos. (DIAS, 2013, p.378)

Após a abolição, as dificuldades mudaram, mas ainda assim permaneciam. Se inserir na sociedade, num contexto de racismo e embranquecimento (NASCIMENTO, 2016, p.610), era complicado para qualquer negro, mas para a mulher negra, principalmente; além do preconceito de cor, havia o forte sexismo. A situação só piorou quando, em 1890, uma lei proibiu as mães solteiras de criarem seus próprios filhos. (DIAS, 2013, p.379) Logicamente, a quase totalidade das mães solteiras do país eram negras alforriadas. Além de perderem a prole como medida de uma sociedade travestida de um velho novo moralismo, a lei ainda conseguiu, em uma jogada magistral, que as crias das negras fossem demovidas para casas 


\section{artigos}

Mulher negra, trabalho e resistência: escravizadas, libertas e profissões no século XIX particulares, perpetuando o trabalho escravo.

Sônia Bento, em sua produção, rememora os estudos sociológicos de Florestan Fernandes e Octávio lanni para analisar a situação gênero-classe dentro dos novos moldes do capitalismo industrial institucionalizado na virada do XIX: "Neste enfoque a mulher negra e vista como sustentáculo da raça uma vez que os homens negros excluídos da nova ordem social por estarem despreparados para assumirem o papel de trabalhadores livres estavam sem condições de manter suas famílias, de modo que à mulher negra restou a responsabilidade pela manutenção material da família." (BENTO, 1995, p.480).

Mais uma vez, nos é oferecida a visão destas mulheres enquanto pilares da família, em contraponto ao modelo de família branco burguês do capitalismo industrial, onde o homem era a fortaleza de sua família. Davis faz coro com Bento ao reivindicar em sua obra o conceito de família matrifocal, mas não de forma pejorativa ou negativa, como quiseram recriar os sociólogos brancos que lera, mas sim revelando que de fato, as relações entre mulheres negras e seus companheiros era muito diversa das expectativas as quais comentamos nas primeiras páginas deste artigo. “Como resultado, ao povo negro supostamente só restava a 'família matrifocal, que enfatiza a primazia da relação entre a mãe e a criança e apenas laços frágeis com o homem"'(DAVIS, 2016, p.26).

Apesar disso, mulheres negras, livres ou forras, em geral não tinham direito à ter suas vidas privadas - pelo menos, não na visão de seus patrões. Elas deveriam equilibrar suas tentativas matrimoniais (tentativas, sim, muitas vezes, visto que à mulher negra o casamento era um luxo ao qual nem toda poderia se dar), suas experiências de maternidade atribuladas e muitas vezes, roubadas, seus engodos familiares com suas tarefas no mundo do trabalho, pelas quais ela não era julgada como a "rainha" de seu lar ou a "mãe desvelada" de seus filhos, mas como qualquer outra trabalhadora que precisa desempenhar bem suas funções. Entretanto, manter ainda assim a vida particular não deixava de ser, de certa maneira, uma forma de resistência, evidenciada neste trecho de Sandra Lauderdale Graham:

Seria grave erro de interpretação das experiências de vida das criadas 


\section{artigos}

\section{Karoline Nascimento Miranda}

desconsiderar suas vidas privadas. As turbulentas horas de diversão na praça pública, na taverna local ou nos três dias anárquicos do carnaval eram momentos relevantes para configurar uma individualidade entre iguais e longe da presença vigilante e desigual dos patrões. (...) Entremeadas nesses momentos, estavam as preocupações constantes com a família, de tal forma que a vida privada e a pública nunca estavam de todo separadas. As criadas carregavam as ansiedades em relação à gravidez, parto, doença, filhos, companheiros e maridos, para dentro de seus locais de trabalho, advertência insistente para os patrões de que as criadas eram na verdade pessoas com vidas completas, vidas essas parcialmente vividas fora de sua jurisdição (GRAHAM, 1992, p.104).

\section{Conclusões}

É delituoso, até para com a justificativa social deste presente artigo, não apontar as similaridades e impactos de nosso objeto de estudo ainda nos dias atuais. Utilizando-nos do trabalho de Paixão e Gomes, Sônia Bento e Sueli Carneiro, é primordial que analisemos as permanências da situação gênero-raça-classe nos mundos do trabalho atuais. Como nos elucida Paixão e Gomes, “Ligar passado e presente numa radical linha direta - tão-somente cronológica ou evolutiva - é sempre perigoso." (PAIXÃO \& GOMES, 2008, p.955). Para tanto, é necessário analisar as tensões sociais e políticas que nos levam a essa afirmação.

De acordo com Bento, que baseou seu trabalho em cruzamento de dados estatísticos com entrevistas pontuais,

O lugar da mulher negra no trabalho está demarcado no imaginário de chefias e profissionais de recursos humanos. E o gueto da subalternização e da realização de atividades manuais. Nos serviços domésticos por exemplo, as negras estão representadas quase três vezes mais do que as brancas (325\% contra 12,7\%) e em atividades tais como serventes cozinheiras e lavadeiras / passadeiras o percentual para negras é o dobro do das brancas (16\% contra 7,6\%)" (BENTO, 1995, p.487).

Ainda permanece, como podemos perceber, a manutenção da ideia de que a mulher negra é a serviçal, a que desempenha as funções do lar e a que recebe a menor remuneração. Dentro dos cargos de chefia, ela não figura. Mas, ainda segundo a autora, essa 


\section{artigos}

Mulher negra, trabalho e resistência: escravizadas, libertas e profissões no século XIX é uma questão pertencente ao âmbito raça-classe, sendo o gênero apenas um realce dessa marginalização.

No que concerne ao gênero, Carneiro se posiciona de maneira assertiva ao dizer que

O que poderia ser considerado como história ou reminiscências do período colonial permanece, entretanto, vivo no imaginário social e adquire novos contornos e funções em uma ordem social supostamente democrática, que mantém intactas as relações de gênero segundo a cor ou a raça instituídas no período da escravidão. As mulheres negras tiveram uma experiência histórica diferenciada que o discurso clássico sobre a opressão da mulher não tem reconhecido, assim como não tem dado conta da diferença qualitativa que o efeito da opressão sofrida teve e ainda tem na identidade feminina das mulheres negras (CARNEIRO, 2011, p.2).

A mulher negra continuou a sofrer golpes no trabalho livre; alguns golpes que sofre até hoje. É inútil analisar a história social do trabalho negro no Brasil de forma homogênea: as negras, além de contribuírem particularmente - e substancialmente - para a economia de subsistência do país, constituíram verdadeiro exemplar de fibra e braço forte. Menores salários e muito mais desvalorização eram só o início de uma batalha constantemente lutada em dois fronts: a cor e o gênero. Os dois, aliados, construíram uma figura trabalhadora forte, que resistiu à todos os contratempos, e circulando entre o doméstico e o público, entre a doméstica e a feirante, e mantém durante séculos importante papel na economia do Brasil.

\section{Referências bibliográficas}

BENTO, Maria Aparecida. "A mulher negra no mercado de trabalho". Revista de Estudos Feministas. Florianópolis. N² 2, 1995.

CARNEIRO, Sueli. “Enegrecer o Feminismo: A Situação da Mulher Negra na América Latina a partir de uma perspectiva de gênero.". Geledés, 06/03/2011. Disponível em: https://www.geledes.org.br/enegrecer-o-feminismo-situacao-da-mulher-negra-na-americalatina-partir-de-uma-perspectiva-de-genero. Acesso em: 30/04/2019

DAVIS, Angela. Mulheres, raça e classe. - $1^{\text {a }}$ ed. - São Paulo: Boitempo, 2016.

DIAS, Maria Odila. "Resistir e sobreviver". In PEDRO, Joana M.; PINSKY, Carla B. Nova História das Mulheres no Brasil. - $1^{\text {a }}$ ed. - São Paulo: Contexto, 2013.

GRAHAM, Sandra L. Proteção e Obediência - criadas e seus patrões no século XIX (1860-1910). São Paulo: Companhia das Letras, 1992. 


\section{artigos}

Karoline Nascimento Miranda

LARA, Silvia Hunold. "Escravidão, cidadania e história do trabalho no Brasil". Proj. História, São Paulo (16) fev, 1998.

NASCIMENTO, Álvaro Pereira. “Trabalhadores negros e o 'paradigma da ausência': contribuições à história social do Trabalho no Brasil". Estudos Históricos, Rio de Janeiro, vol. 29, n. 59, p. 607-626, setembro-dezembro 2016.

NEPOMUCENO, Bebel. “Protagonismo ignorado." In PEDRO, Joana M.; PINSKY, Carla B. Nova História das Mulheres no Brasil. - 1ª ed. - São Paulo: Contexto, 2013.

PAIXÃO, Marcelo GOMES, Flavio. "Histórias das diferenças e das desigualdades revisitadas: notas sobre gênero, escravidão, raça e pós-emancipação." Revista Estudos Feministas, vol.16 no.3 Florianópolis Sept./Dec. 2008

PRIORE, Mary Del. A mulher na história do Brasil. São Paulo: Contexto, 1988.

RAGO, Margareth. "A mulher na historiografia brasileira". In: SILVA, Zélia Lopes (Org.). Cultura Histórica em Debate. São Paulo: UNESP, 1995.

REIS, João José. “A greve negra de 1857 na Bahia". Revista USP, n. 18, 1993, p. 8-29.

SOARES, Cecilia Moreira. "As Ganhadeiras: mulher e resistência negra em Salvador no século XIX.". In AFRO-ÁSIA, No 17, pp. 57-71; Centro de Estudos Afro-Orientais, Bahia, Salvador: EUFBA, 1996. 